\title{
Synchronization of Codification of Unspecified Schizophrenia Againts Back-Referral System of Mirit Public Health Center
}

\author{
Nur Hayati Munawaroh*, Ndari Afriyani, Sri Wahyuni, Triyo Rachmadi \\ Politeknik Dharma Patria Kebumen, Middle Java, Indonesia \\ *corresponding author, email: nurhayatimunawarohmtds@gmail.com
}

\section{ARTICLE INFO}

Article history

Received 08/16/21

Revised 10/03/21

Accepted 10/13/21

Keywords

Synchronization

Back-Referral System

Codification

Schizophrenia

\section{ABSTRACT}

Background: The disease classification system is a grouping of diseases following the International Statistical Classification of Diseases and Related Health Problems Tenth Revisions ICD-10. The coding application must be in accordance with ICD-10 to obtain a valid code in disease indexing, national, international reporting of morbidity and mortality, analysis of health care costs, and epidemiological and clinical research. The diagnosis of schizoaffective disorder is made if schizophrenia and affective disorder are symptoms based on the ICD-10 diagnostic criteria. This study aims to determine the synchronization of the codification of unspecified schizophrenia and determine the factors that influence it against the back-referral system at the Mirit Health Center. Method: This research is qualitative research with a descriptive approach. Respondents were four officers, i.e. one doctor, one medical record officer, one person holding a mental program, one pharmacy officer. The number of observed medical record documents was 96 data with research indicators of accuracy and completeness of the diagnosis code in patients referred from First Level Health Facilities (FKTP) to Advanced Health Facilities (FKTL). Result: The results showed 30 referrals, with nine referrals having the accuracy of the patient referral diagnosis code. The back-referral program (PRB) for mental illness at the Mirit Health Center, in collaboration with Mbah Marsio's mental health rehabilitation centre, was carried out well. However, the implementation of the Chronic Disease Management program (Prolanis) for mental health was still not good. Conclusion: There are many unsynchronized codifications. It is recommended to conduct an evaluation where they communicate each other about the patient's condition to supervise the implementation of Referback Patients, especially to specialists who write the back-referral form.

This is an open access article under the CC-BY-SA license.

\section{Introduction}

In 2021, people with mental disorders, including Unspecified Schizophrenia, reach 450 million people [1]. Cases of mental disorders in Indonesia increased in 2018. This increase is evidenced by the fact that per 1000 households, there are seven households with People with Mental Disorders (ODGJ), which is estimated to total 450 thousand severe ODGJ [2-4]. There are 5,000 people with Schizophrenia Unspecified in Kebumen Regency [5]. In the first trimester at the Mirit Health Center, there were 96 people with 30 patients referred to the Advanced Health Facilities (FKTL) [6-8].

Public Health Center (Puskesmas) is one of the health service facilities owned by the regional government that organizes the first level of Community Health Efforts (UKM) and Individual Health Efforts (UKP), prioritizing promotive and preventive efforts to achieve the highest public health status in their working areas [9-10]. Puskesmas provide services for the national health insurance program. With this program, the community gets services in stages 
from the First Level Health Facilities (FKTP) and/or referral to the FKTL [3-5]. One type of disease that is included in the national health insurance program as one of the optimizations of health services is Unspecified Schizophrenia Disease. The role of the puskesmas in dealing with mental disorders is to provide medicine, become a consultation centre, and provide referrals [11].

The referral system is created because of the limitations of FKTP in providing services so that referrals are made as an alternative that must be taken [14-16]. Referrals are considered confirmed if the health facility receiving the referral receives the patient and sends the referral back. Back-Referral program services are health services provided to patients with chronic diseases with stable conditions and still require long-term treatment or nursing care at the FKTP on the recommendation of the treating specialist/sub-specialist [17]. The referral system has procedures that must be followed by FKTP, such as referral levels, information submitted to families or patients, transportation facilities used, referral letters and back referrals [6-8].

The Puskesmas has an information system, namely the Puskesmas Information System. The Puskesmas Information System is an arrangement that provides information to assist the decision-making process in implementing the management of the Puskesmas to achieve its activity targets [1-2]. Codification or Coding is one of the medical record data processing activities to provide a code with letters or numbers or a combination of letters and numbers representing data components. The code for the diagnosis of disease classification that applies is by using the International Statistical Classification of Disease and Related ICD-X, while the International Classification of Procedures in Medicine (ICOPIM) and The International Classification of Diseases, Ninth Revision, Clinical Modification (ICD-IX-CM). ) is used to code actions and computers to code diseases and medical procedures. The codification aims to produce health information for leaders to improve the efficiency and quality of services for hospitals and health centres [12-13]. Schizophrenia Unspecified is given the disease codification F20.9.

Synchronization of filling out the referral form from the FKTP with the back referral from the FKTL is required for a re-consultation to the hospital. If it is considered stable and under control, the next therapy can be continued at the FKTP [18-19]. This study is used to determine the suitability or synchronization between entry for the codification of unspecified schizophrenia at the puskesmas and the factors that influence it.

\section{Method}

This research is qualitative research with a descriptive approach and using a crosssectional design. The research time is January-March 2021 at the Mirit Health Center. This study uses primary data obtained from observations and interviews and secondary data derived from 96 patient medical record files. There are four resource persons, namely; 1 ) Doctor (1 person) as one of the health workers who is responsible for the patient to be referred and ascertains the cause of the referral; 2) The holder of the mental case program (1 person) who is authorized and responsible for the specifics of mental illness; 3) Medical record officer (1 person) who knows about documents, knows the course of the patient's illness, and is responsible for making referrals for patients who will be referred to FKTL; 4) Pharmacy (1 person) who is responsible for the availability of drugs at the puskesmas. The data analysis technique used is descriptive qualitative.

\section{Results and Discussion}

\subsection{Results}

Based on the observations made, there are 30 referral cases of Schizophrenia Unspecified (F20.9). A total of 9 referrals contained the accuracy of the patient's referral diagnosis code, while 21 were out of sync because the coding of the referral diagnosis was still changing. There is the addition of a new diagnosis behind it, and there is no communication between FKTL to FKTP. The following interview results support the results of these observations:

"The PRB (back-referral Program) is handled at the puskesmas; if at the puskesmas there are no facilities and drugs, it will be done a back-referral process. Suppose the PCR status has been done a back-referral, in that case, it must have been PRB from the hospital because the hospital determines PRB. The cause of frequent changes in coding is because there is a follow-up examination from the hospital and the medical record itself follows the codification that has been determined." (Informant 3)

Mirit Health Center has implemented PRB well, but the implementation of mental Prolanis (Chronic Disease Management program) is still not good. Patients at the Mirit Health Center 
have not yet received back referrals from the FKTL and provided evidence to the FKTP. As the following interview results:

"With the current condition, PRB at the Mirit Health Center has been going well. However, the prolanis does not go well because the PRB and the prolanis are different ...... FKTP always provides evidence in the form of a referral to the FKTL, but not all patients have provided proof to be given to the FKTP after returning to the puskesmas for treatment." (Informant 1).

It is supported by a statement from the officer handling the mental program who helped implement Schizophrenia Unspecified (F20.9) treatment activities at the ODJG rehabilitation centre. Cases of disease that can be referred, all with the approval and recommendation of a doctor. Patients who ask for referrals do not immediately receive referrals, such as the following statement:

"The case of PRB patients depends on the doctor; we only provide counselling to ODGJ (people with mental disorders) patients because, as far as I know, the referral patient is an approval from the doctor, as according to 144 disease diagnoses that should not be referred; for example, some patients ask for referrals but do not get recommendations from doctors, so referrals will not be made, because it can affect the achievement of KBK at the puskesmas" (Informant 2).

PRB patients who brought evidence of PRB from the hospital to return to the FKTP were nine patients. While the other 21 patients immediately gave them to the doctor when they visited for treatment again, then they were recorded in a ledger by the nurse. The medical recorder is assigned to make a referral by a doctor with a diagnosis code following the doctor's recommendation, such as the informant's statement as follows:

"For RM (medical recorder) himself did not receive the PRB sheet, the doctors and nurses who received it, when they returned to the medical records department (we) only received the RM written by the doctor and just entered. The doctor only orders the medical record officer himself to make a referral, not to determine the codification, because the doctor decides. Except for those related to the clinic, if the hospital changes the mental clinic because the closure is moving to the neurology clinic." (Informant 3).

The reason the patient was referred was because of the doctor's decision where the patient had to get a further examination and more adequate facilities. In addition, this is because the stock of drugs in pharmacies is depleted or incomplete, as stated in the following statement:

"For drug claims, the patient is referred depending on the drug; the patient is not referred if the drug is available. Referrals occur because there may be non-existent drug stocks or incomplete drug stocks, and it depends on the doctor's decision whether to be referred to FKTL or not." (Informant 4).

\subsection{Discussion}

Mirit Health Center is one of the FKTPs in Kebumen Regency, which provides first-rate health services in the National Health Insurance program. Therefore, people who will receive health services with a diagnosis of Unspecified Schizophrenia Disease, if advised by a doctor to be referred to the FKTL, will receive a referral from the Mirit Health Center in the form of a referral from the FKTP in order to receive health services, namely specialist medical services with a diagnosis of Unspecified Schizophrenia disease in referral for FKTL. In addition, the community will get a back-referral from FKTL in the form of a Back-Referral to get services back at the Mirit Health Center as a First Level Health Service Facility $[14,15]$.

The coding process defined by the coder uses ICD-10. Before coding the Schizophrenia Unspecified (F20.9) diagnosis, the Medical Record section must review the patient's medical record data to find deficiencies, errors, or mistakes [20-21]. Therefore, the accuracy of the medical record contents is a requirement for determining the diagnosis, so collaboration between doctors and coders plays a very important role in synchronizing disease diagnosis $[22,23]$.

Referral information given to the patient by the doctor who will refer back the patient provides information in advance to the patient about the condition of his illness, medications that are still being continued, things that can and cannot be done, a follow-up that is still needed both at the puskesmas and for re-admission to the hospital. And if it is considered stable and controlled, it can continue the next therapy at the first level health facility or puskesmas. 
Suppose the patient's referral has been received at the hospital. In that case, the response letter is sent to the Puskesmas so that in the future, this referral program can be improved by adding more diagnoses of diseases whose treatment can be continued at the puskesmas. Patients who can be referred back are patients with stable and controlled conditions, and continued therapy at the puskesmas is recommended by specialist doctors from the hospital [24,25].

Based on the Regulation of the Minister of Health Number 001 of 2012 concerning the Referral System for Individual Health Services, Article 15 states that "The letter of introduction for the referral must at least contain the patient's identity, the results of the examination (anamnesis, physical examination and supporting examinations) that have been carried out, work diagnosis, therapy and/or action that has been given, the purpose of the referral, and the name and signature of the health worker providing the service. The completeness of filling in the back-referral column with clear writing has been carried out by doctors who provide direct services to patients. Information about the patient's condition is sufficient to explain in the referral letter, especially therapy or drugs that will be continued at the puskesmas. It is very important to do this because clear writing makes it easier for doctors at the puskesmas to provide further therapy recommended by specialist doctors who treat patients [26].

The basis for making FKTP Referrals and Referral Letters in health services with a diagnosis of Unspecified Schizophrenia Disease, the system will first decide whether a positive patient has schizophrenia or not by using the IF-THEN rules. If a positive patient is affected by schizophrenia, a probability calculation process will be carried out using the Bayesian Network method to determine which type of schizophrenia sufferers are affected. Codification is carried out based on the medical record file so that the Codification of Schizophrenia Unspecified Disease can be entered in the FKTP Referral Letter and Return Referral Letter [16,17].

The PRB letter is not optimal and not good in the SOP, according to the statement "during the direct patient referral process, if the patient is in critical condition the doctor will continue to monitor the patient's condition" where point 8 contains "referral recipients are required to provide information to the referrer regarding the progress of the patient's condition. after finishing providing services" as stated in the SOP at the Mirit Health Center [21].

Synchronization Analysis of Patient Referral Diagnostic Codes at Mirit Health Center Against Outgoing Diagnosis based on research results from 30 samples showed that the accuracy of the Mirit Health Center's exit diagnosis code was nine referrals. In contrast, the non-synchronized diagnosis of patient referrals at Mirit Health Center was 21 referrals. This is because, among other things, the determination of the diagnosis that is not appropriate by the doctor at the Puskesmas, causing the coding result to be wrong or the diagnosis to be correct, but the Medical Record officer incorrectly determines the code. This causes the coding results to be inaccurate. The doctor's diagnosis is not clear, and then it is read incorrectly by the Medical Record officer, resulting in incorrect coding results. The cause of frequent discrepancies in the referral code between FKTP and FKTL is that there is still treatment and follow-up treatment in FKTL, there is no explanation of the diagnosis code, and there is no explanation for a follow-up examination in the PRB referral letter. PRB is the duty of the Hospital as evidence that the referred patient is returned to the Puskesmas. Of the 30 samples of PRB at the Mirit Health Center that were sent from the Hospital, some did not provide a letter of evidence from the Hospital to return to the FKTP, so that PRB at the Mirit Health Center had not been going well.

From these results, it can be concluded that the synchronization of the diagnostic code on BPJS patient referrals at the Mirit Health Center for outgoing diagnoses has not been maximized because the observation accuracy results are not good. The following elements must be monitored during the coding process to obtain accurate codes [24-26].

Consistent when coded by different officers, the code remains the same (reliability). From the results of in-depth interviews with medical personnel, they stated that the ability of coders in coding disease diagnoses and actions was good because they were given adequate training. Besides being equipped with ICD 10 and ICD 9 CM, they are also equipped with a program to determine disease codes and actions. Correct code according to diagnosis and action (validity). The results of in-depth interviews with medical personnel revealed that the diagnosis's completeness could create a valid diagnosis code. The valid code is determined by the completeness of the diagnosis and the code itself. Includes all diagnoses and actions in the medical record (completeness). The accuracy of coding can be seen from several elements of coding quality, namely consistency when coded by different officers with the same code (reliability), giving the right code according to the diagnosis and 5 actions (validity), covering all diagnoses and actions in the medical record (completeness) [1]. On-time (timelines). The 
results of in-depth interviews with informants revealed that they coded disease diagnoses on time every day; no code became homework for today or coded for tomorrow [27].

Sufficient training for coders will affect their ability to synthesize some information and set the correct code. In addition, the experience, attention, and diligence or thoroughness of the coder also affects the accuracy of coding. Factors that cause coding errors are the ability of the coder to determine the code that is less precise, less thorough and the coder's lack of ability to read the diagnosis [28]. Important factors that affect coding accuracy include medical personnel, coding officers or coders, completeness of medical record documents, and policies [14-15]. Accurate, complete and consistent diagnostic coding will result in quality data. Accuracy in providing diagnosis codes is an important thing that medical recorders must consider because the quality of coded data is vital for Health Information Management personnel. The accuracy of diagnostic data is crucial in clinical data management, cost collection, and other matters related to health care and services [29].

Filling out a complete referral can reflect the quality of the existing referrals at the puskesmas or health service facilities concerned. Given the importance of the content of the referral, if the reference is not filled in completely, misunderstandings can occur between the sender of the referral and the recipient of the referral. Therefore, the quality of referrals depends on the completeness of the referrals. Implementing the referral system at the Mirit Health Center does not always run as expected; sometimes, some problems occur in implementing this referral. The author has made observations about the problems that arise in the referral system. Referral systems contribute to high standards of health care by limiting over-medicalization, clear delegation of duties between specialists and general practitioners, and freeing up specialists to develop their specialized knowledge, and cost appropriate medical care [26].

By filling out a complete referral, it can reflect the quality of the existing referrals at the puskesmas or health service facilities concerned. Given the importance of the content of the referral, if the reference is not filled in completely, misunderstandings can occur between the sender of the referral and the recipient of the referral. Therefore, the quality of referrals depends on the completeness of the referrals (30).

\section{Conclusion}

The PRB (Back-Referral Program) at the Mirit Health Center has been implemented well, but mental prolanis (Chronic Disease Management program) is still not good. Codification in PRB patients has not been synchronized. It is recommended to carry out a joint evaluation between FKTP and FKTL to create a system where these parties can communicate about the patient's condition to supervise the implementation of the back-referral patients, especially to specialist doctors who write the back-referral form.

\section{Declaration}

Conflict of Interest: No conflic of interest in this study Acknowledgments:

\section{Referensi}

1. Chen, X., Tong, Y., Shi, Z., Chen, H., Yang, Z., Wang, Y., Chen, L., \& Yu, J. (2019). Noninvasive Molecular Diagnosis of Craniopharyngioma with MRI-Based Radiomics Approach. BMC neurology, 19(1), 6. https://doi.org/10.1186/s12883-018-1216-z

2. Keshavan, M. S., Collin, G., Guimond, S., Kelly, S., Prasad, K. M., \& Lizano, P. (2020). Neuroimaging in Schizophrenia. Neuroimaging clinics of North America, 30(1), 73-83. https://doi.org/10.1016/j.nic.2019.09.007

3. Silva, M. A., \& Restrepo, D. (2019). Functional Recovery in Schizophrenia. Recuperación funcional en la esquizofrenia. Revista Colombiana de psiquiatria (English ed.), 48(4), 252260. https://doi.org/10.1016/j.rcp.2017.08.004

4. Mamakou, V., Thanopoulou, A., Gonidakis, F., Tentolouris, N., \& Kontaxakis, V. (2018). Schizophrenia and Type 2 Diabetes Mellitus. Psychiatrike = Psychiatriki, 29(1), 64-73. https://doi.org/10.22365/jpsych.2018.291.64

5. Vita, A., \& Barlati, S. (2018). Recovery From Schizophrenia: Is It Possible?. Current opinion in psychiatry, 31(3), 246-255. https://doi.org/10.1097/YCO.0000000000000407

6. Palomar-Ciria, N., Cegla-Schvartzman, F., Lopez-Morinigo, J. D., Bello, H. J., Ovejero, S., \& Baca-García, E. (2019). Diagnostic Stability of Schizophrenia: A systematic review. Psychiatry research, 279, 306-314. https://doi.org/10.1016/j.psychres.2019.04.020 
7. Hosak, L., Sery, O., Sadykov, E., \& Studnicka, J. (2018). Retinal Abnormatilites as a Diagnostic or Prognostic Marker of Schizophrenia. Biomedical papers of the Medical Faculty of the University Palacky, Olomouc, Czechoslovakia, 162(3), 159-164. https://doi.org/10.5507/bp.2018.035

8. Jaaro-Peled, H., \& Sawa, A. (2020). Neurodevelopmental Factors in Schizophrenia. The Psychiatric clinics of North America, 43(2), 263-274. https://doi.org/10.1016/.jpsc.2020.02.010

9. Emengo, V. N., Williams, M. S., Odusanya, R., Uwemedimo, O. T., Martinez, J., Pekmezaris, R., \& Kim, E. J. (2020). Qualitative Program Evaluation of Social Determinants of Health Screening and Referral Program. PloS one, 15(12), e0242964. https://doi.org/10.1371/journal.pone.0242964

10. Davis, J. M., Thomas, L. C., Dirkes, J. E., Datta, S. K., \& Dennis, P. A. (2020). Comparison of Referral Methods Into A Smoking Cessation Program. Journal of comparative effectiveness research, 9(11), 807-815. https://doi.org/10.2217/cer-2020-0004

11. Zhu, E., Ahluwalia, J. S., \& Laws, M. B. (2020). An Evaluation of Connect for Health: A Social Referral Program in RI. Rhode Island medical journal (2013), 103(5), 65-69.

12. Barth, C., Colombet, I., Montheil, V., Huillard, O., Boudou-Rouquette, P., Tlemsani, C., Alexandre, J., Goldwasser, F., \& Vinant, P. (2020). First Referral to an Integrated OncoPalliative Care Program: A Retrospective Analysis of Its Timing. BMC palliative care, 19(1), 31. https://doi.org/10.1186/s12904-020-0539-x

13. Venkataramani, M., Pollack, C. E., Yeh, H. C., \& Maruthur, N. M. (2019). Prevalence and Correlates of Diabetes Prevention Program Referral and Participation. American journal of preventive medicine, 56(3), 452-457. https://doi.org/10.1016/j.amepre.2018.10.005

14. Berry, C., Paul, M., Massar, R., Marcello, R. K., \& Krauskopf, M. (2020). Social Needs Screening and Referral Program at a Large US Public Hospital System, 2017. American journal of public health, 110(S2), S211-S214. https://doi.org/10.2105/AJPH.2020.305642

15. Jarczyk, K. S., Pieper, P., Brodie, L., Ezzell, K., \& D'Alessandro, T. (2018). An Integrated Nurse Practitioner-Run Subspecialty Referral Program for Incontinent Children. Journal of pediatric health care : official publication of National Association of Pediatric Nurse Associates \& Practitioners, 32(2), 184-194. https://doi.org/10.1016/j.pedhc.2017.09.015

16. Salam A. Sistem Pakar Diagnosa Penyakit Skizofrenia Dengan Forward Chaining Dan Bayesian Network. JOINS (Journal Inf Syst. 2021;6(1):72-82.

17. Nørgaard, H., Schou Pedersen, H., Fenger-Grøn, M., Vestergaard, M., Nordentoft, M., Laursen, T. M., \& Mors, O. (2019). Schizophrenia and Attendance in Primary Healthcare: A Population-Based Matched Cohort Study. Scandinavian journal of primary health care, 37(3), 358-365. https://doi.org/10.1080/02813432.2019.1639927

18. Puspitasari, I. M., Sinuraya, R. K., Rahayu, C., Witriani, W., Zannah, U., Hafifah, A., Ningtyas, A. R., \& Vildayanti, H. (2020). Medication Profile and Treatment Cost Estimation Among Outpatients with Schizophrenia, Bipolar Disorder, Depression, and Anxiety Disorders in Indonesia. Neuropsychiatric disease and treatment, 16, 815-828. https://doi.org/10.2147/NDT.S240058

19. Poletti, M., Gebhardt, E., Pelizza, L., Preti, A., \& Raballo, A. (2020). Looking at Intergenerational Risk Factors in Schizophrenia Spectrum Disorders: New Frontiers for Early Vulnerability Identification?. Frontiers in psychiatry, 11, 566683. https://doi.org/10.3389/fpsyt.2020.566683

20. Hernandez-Ibarburu, G., Perez-Rey, D., Alonso-Oset, E., Alonso-Calvo, R., de Schepper, K., Meloni, L., \& Claerhout, B. (2019). ICD-10-CM Extension with ICD-9 Diagnosis Codes to Support Integrated Access to Clinical Legacy Data. International journal of medical informatics, 129, 189-197. https://doi.org/10.1016/j.ijmedinf.2019.06.010

21. Hernandez-Ibarburu, G., Perez-Rey, D., Alonso-Oset, E., Alonso-Calvo, R., Voets, D., Mueller, C., Claerhout, B., \& Custodix, N. V. (2019). ICD-10-PCS Extension with ICD-9 Procedure Codes to Support Integrated Access to Clinical Legacy Data. International journal of medical informatics, 122, 70-79. https://doi.org/10.1016/j.ijmedinf.2018.11.002

22. Glerum, K. M., \& Zonfrillo, M. R. (2019). Validation of an ICD-9-CM and ICD-10-CM Map to AIS 2005 Update 2008. Injury prevention : journal of the International Society for Child and Adolescent Injury Prevention, 25(2), 90-92. https://doi.org/10.1136/injuryprev-2017-042519

23. Karimah RN, Setiawan D, Nurmalia PS. Diagnosis Code Accuracy Analysis Of Acute Gastroenteritis Disease Based on Medical Record Document in Balung Hospital Jember. $J$ Agromedicine Med Sci. 1970;2(2):12.

24. Kelley, A. S., Ferreira, K. B., Bollens-Lund, E., Mather, H., Hanson, L. C., \& Ritchie, C. S. 
(2019). Identifying Older Adults With Serious IIIness: Transitioning From ICD-9 to ICD10. Journal of pain and symptom management, 57(6), 1137-1142. https://doi.org/10.1016/j.jpainsymman.2019.03.006

25. Hess, L. M., Zhu, Y. E., Sugihara, T., Fang, Y., Collins, N., \& Nicol, S. (2019). Challenges of Using ICD-9-CM and ICD-10-CM Codes for Soft-Tissue Sarcoma in Databases for Health Services Research. Perspectives in health information management, 16(Spring), 1a.

26. Mayssara A. Abo Hassanin Supervised A. Tono. Pap Knowl Towar a Media Hist Doc. 2018;4:49-59.

27. Karimah RN, Setiawan D, Nurmalia PS. Diagnosis Code Accuracy Analysis Of Acute Gastroenteritis Disease Based on Medical Record Document in Balung Hospital Jember. Vol. 2, Journal of Agromedicine and Medical Sciences. 1970. 12 p.

28. Cai, C. X., Michalak, S. M., Stinnett, S. S., Muir, K. W., Fekrat, S., \& Borkar, D. S. (2021). Effect of ICD-9 to ICD-10 Transition on Accuracy of Codes for Stage of Diabetic Retinopathy and Related Complications: Results from the CODER Study. Ophthalmology. Retina, 5(4), 374-380. https://doi.org/10.1016/j.oret.2020.08.004

29. Zhou, L., Cheng, C., Ou, D., \& Huang, H. (2020). Construction of a semi-automatic ICD-10 coding system. BMC medical informatics and decision making, 20(1), 67. https://doi.org/10.1186/s12911-020-1085-4

30. Journal U, Wulandari PA, Piksi P, Bandung G, Barat J. Analysis Of Accuracy Of Cjs Patient Diagnosis Code In Buayan Health Center On The Outdoor Diagnosis Of Pku Muhammadiyah Gombong. 2021;2(2):6-10. 